\title{
The Association between Social Contacts and Depressive Symptoms among Elderly Koreans
}

\author{
Jieun Yang ${ }^{1,2}$, Eun-Cheol Park ${ }^{2,3}$, Sang Ah Lee ${ }^{1,2}$, Joo Eun Lee ${ }^{2}$, \\ Dong-Woo Choi ${ }^{1,2}$, Wonjeong Chae ${ }^{1,2}$, and Sung-In Jang ${ }^{2,3}{ }^{凶}$ \\ ${ }^{1}$ Department of Public Health, Graduate School, Yonsei University, Seoul, Republic of Korea \\ ${ }^{2}$ Institute of Health Services Research, Yonsei University, Seoul, Republic of Korea \\ ${ }^{3}$ Department of Preventive Medicine, Yonsei University College of Medicine, Seoul, Republic of Korea
}

\begin{abstract}
Objective South Korea has an increasing aging population; thus, the management of depressive symptoms in elderly individuals is important. In this population, fewer social contacts might be a risk factor for depressive symptoms. We examined associations between the frequency of social contacts and depressive symptoms among elderly Koreans and factors associated with these symptoms.

Methods Data from 62,845 individuals over 65 years of age enrolled in the 2015 Community Health Survey were used in this study. Logistic regression was performed to test the association between depressive symptoms and social contacts.

Results Individuals who had contact with neighbors less than once a week were more likely to experience depressive symptoms [odds ratio (OR): 1.22, 95\% confidence interval (CI): 1.10-1.35] compared to those who had contact more than once a week. Individuals who had frequent contact with neighbors and friends, neighbors and relatives, or all three groups were significantly less likely to experience depressive symptoms.

Conclusion The frequency of social contact with neighbors was the most powerful factor associated with elderly adults' depressive symptoms among other social relationships. Additional senior welfare centers may facilitate the ability of elderly individuals in meeting neighbors, thereby reducing the risk of depressive symptoms.

Psychiatry Investig 2018;15(9):861-868
\end{abstract}

Key Words Depressive symptoms, Older adults, Social contacts, Neighbors.

\section{INTRODUCTION}

The population of South Korea is increasingly aging. The proportion of the population aged 65 years or over in South Korea was approximately $7 \%$ in 2000 and is expected to increase to $14 \%$ and $21.1 \%$ by 2018 and 2026, respectively, ${ }^{1}$ indicating that South Korea is an aged society in 2018 and will be a super-aged society by $2026 .{ }^{2}$ In an aging country, depression among older adults is an important issue. ${ }^{3}$ Depression is a major cause of suicide; the suicide rate in South Korea ranked highest among Organisation for Economic Cooperation and Development (OECD) members in 2014, ${ }^{4}$ and its rate in the

Received: April 5, 2018 Revised: June 25, 2018

Accepted: June 28, 2018

$\triangle$ Correspondence: Sung-In Jang, MD, PhD

Department of Preventive Medicine and Institute of Health Services Research, Yonsei University College of Medicine, 50 Yonsei-ro, Seodaemun-gu, Seoul 03722, Republic of Korea

Tel: +82-2-2228-1863, Fax: +82-2-392-8133, E-mail: JANGSI@yuhs.ac

(a) This is an Open Access article distributed under the terms of the Creative Commons Attribution Non-Commercial License (https://creativecommons.org/licenses/bync/4.0) which permits unrestricted non-commercial use, distribution, and reproduction in any medium, provided the original work is properly cited.
Korean elderly is more steeply increasing than in elderly populations of other countries. ${ }^{5}$ If older adults have suicidal ideation, their risk of committing suicide is much higher than that in young people. ${ }^{6}$ In addition, according to the national statistics, the rate of single-person households among total households over 60 years old was 30\% in 2015, but that in 2,045 will be $54 \%{ }^{7}$ Therefore, problems of increasing older adults' loneliness and depression is a crucial social issue to solve in this rapidly aging society.

According to the social convoy model, ${ }^{8}$ the social convoy gives a protective ground, and dynamically moves through one's life. In the social convoy model, age is one of the crucial factors that consist of the social convoy, and older adults might narrow the social surroundings and limit their interacting to the most satisfactory individuals. ${ }^{10}$ Structural aspects, function, and quality of the convoys significantly relate to well-being in adult. Among those factors, structural aspects of the social convoy include network size, number of network members, marital status, social contact frequency, and participating in social activities. ${ }^{10}$ Previous studies have found that a lack of social 
support is correlated with increased depressive symptoms among older adults. ${ }^{11,12}$ However, few studies focused on associations between different types of social contact frequency, which is one of the structural aspects of the social convoy, and depressive symptoms among older adults.

Therefore, the present study examined the association between social contact frequency and depressive symptoms among elderly Koreans. We also performed subgroup analyses to identify associations between different types of social contacts and depressive symptoms among elderly according to demographic and socioeconomic factors such as age group, having a spouse, income level, and employment status.

\section{METHODS}

\section{Study population}

This study evaluated data from the nationwide Community Health Survey (CHS), which has been conducted annually since 2008 in individuals aged 19 years and older by the Korean Centers for Disease Control and Prevention (KCDC). We used data from the $2015 \mathrm{CHS}$. The study's population was limited to older adults (aged $\geq 65$ years) in South Korea and individuals less than 65 years of age $(\mathrm{n}=164,629)$ and individuals with missing data $(n=1,084)$ were excluded. Therefore, the present study evaluated data from 62,845 individuals. The CHS received consent from study participants before the starting of the survey. The study design was approved by the KCDC Institutional Review Board (IRB No. 2014-08EXP-09-4C-A).

\section{Variables}

The main variable of interest was the social contacts, which were assessed using self-reported data based on responses to the three CHS questions regarding the frequency of social contacts, which included both face-to-face and telephone contact: "How often do you have contact with your closest relatives?", "How often do you have contact with your closest neighbors?", and "How often do you have contact with your closest friends?" In the first question, 'relatives' included family members. There were six possible responses: "<once a month," "once a month," "two to three times a month," "once a week," "two to three times a week," or " $\geq$ four times a week." We categorized the responses into two groups: "rarely" (<once a week) or "frequently" ( $\geq$ once a week).

The dependent variable was defined as depressive symptoms and was evaluated using self-reported data based on responses to the CHS question "Did you experience any moods like sadness or despair for more than two consecutive weeks during the previous year?" The responses were categorized as "yes" or "no."

The analyses were adjusted for the individuals' demograph- ic, socioeconomic, and health-related characteristics. The demographic characteristics were age $(65-69,70-74,75-79$, or $\geq 80$ years), sex (male or female), and having a spouse (yes or no). The socioeconomic characteristics were monthly income level (low, lower-middle, upper-middle, or high according to the responses to the multiple choice survey question: $<\$ 1,000, \$ 1,000$ to $\$ 3,000, \$ 3,000$ to $\$ 5,000, \geq \$ 5,000$, respectively), educational level (elementary school or lower, middle school, high school, or college or higher), and labor status (active or non-active during the last week). The health-related factors were perceived health status (good, normal, or bad); physical activity (sufficient or insufficient: whether doing moderate-vigorous physical activity or not); perceived stress status (high or low), current drinker (yes or no); current smoker (yes or no) and having chronic diseases including diagnosed hypertension, diabetes mellitus, and arthritis (yes or no). All covariates were used as categorical variables.

\section{Statistical analysis}

The individuals' general characteristics were compared using chi-square tests to identify differences between individuals who did or did not experience depressive symptoms for more than two weeks during the previous year. After adjusting for demographic, socioeconomic, and health-related covariates, we performed logistic regression analysis to evaluate the association between depressive symptoms and the frequency of social contacts using weighted data. The results were reported as odds ratios (ORs) and confidence intervals (CIs). Subgroup analyses were also performed stratified by age group, having a spouse, income level, and labor status. Differences were regarded as statistically significant for p-values $<0.05$. All statistical analyses were performed using SAS software (version 9.4, SAS Institute, Cary, NC, USA).

\section{RESULTS}

Table 1 shows the general characteristics of the study population. Among the 62,845 participants, 4,729 (7.5\%) reported experiencing depressive symptoms for more than two consecutive weeks during the previous year and 58,116 (92.5\%) reported not experiencing depressive symptoms. Among total participants, 25,746 (41.0\%) were men, and 37,099 (59.0\%) were women. 39,155 (62.3\%) participants had a spouse, and 23,690 (37.7\%) did not have a spouse. 24,638 (39.2\%) were economically active, and 38,207 (60.8\%) were not.

Table 2 shows the factors that were associated with depressive symptoms and that the frequency of certain social contacts was significantly associated with depressive symptoms. Individuals who had contact with relatives less than once a week were significantly more likely to experience depressive 
Table 1. General characteristics of the study population

\begin{tabular}{|c|c|c|c|c|}
\hline \multirow{2}{*}{ Variables } & \multirow{2}{*}{$\begin{array}{c}\text { Total }(\mathrm{N}=62,845) \\
\mathrm{N}(\%)\end{array}$} & \multicolumn{2}{|c|}{ Depressive symptoms } & \multirow{2}{*}{$\mathrm{p}$-value } \\
\hline & & Yes, N (\%) & No, N (\%) & \\
\hline Contact with relatives & & & & $<0.0001$ \\
\hline$<$ Once a week & $25,107(40.0)$ & $2,200(8.8)$ & $22,907(91.2)$ & \\
\hline$\geq$ Once a week & $37,738(60.1)$ & $2,529(6.7)$ & $35,209(93.3)$ & \\
\hline Contact with neighbors & & & & $<0.0001$ \\
\hline$<$ Once a week & $13,590(21.6)$ & $1,327(9.8)$ & $12,263(90.2)$ & \\
\hline$\geq$ Once a week & $49,255(78.4)$ & $3,402(6.9)$ & $45,853(93.1)$ & \\
\hline Contact with friends & & & & $<0.0001$ \\
\hline$<$ Once a week & $34,379(54.7)$ & $2,882(8.4)$ & $31,497(91.6)$ & \\
\hline$\geq$ Once a week & $28,466(45.3)$ & $1,847(6.5)$ & $26,619(93.5)$ & \\
\hline Age (years) & & & & 0.0003 \\
\hline $65-69$ & $17,973(28.6)$ & $1,224(6.8)$ & $16,749(93.2)$ & \\
\hline $70-74$ & $17,952(28.6)$ & $1,393(7.8)$ & $16,559(92.2)$ & \\
\hline $75-79$ & $14,665(23.3)$ & $1,138(7.8)$ & $13,527(92.2)$ & \\
\hline$\geq 80$ & $12,255(19.5)$ & $974(8.0)$ & $11,281(92.1)$ & \\
\hline Sex & & & & $<0.0001$ \\
\hline Men & $25,746(41.0)$ & $1,327(5.2)$ & $24,419(94.9)$ & \\
\hline Women & $37,099(59.0)$ & $3,402(9.2)$ & $33,697(90.8)$ & \\
\hline Existence of spouse & & & & $<0.0001$ \\
\hline Yes & $39,155(62.3)$ & $2,267(5.8)$ & $36,888(94.2)$ & \\
\hline No & $23,690(37.7)$ & $2,462(10.4)$ & $21,228(89.6)$ & \\
\hline Monthly income & & & & $<0.0001$ \\
\hline Low & $34,322(54.6)$ & $3,205(9.3)$ & $31,117(90.7)$ & \\
\hline Lower-middle & $20,310(32.3)$ & $1,145(5.6)$ & $19,165(94.4)$ & \\
\hline Upper-middle & $5,536(8.8)$ & $253(4.6)$ & $5,283(95.4)$ & \\
\hline High & $2,677(4.3)$ & $126(4.7)$ & $2,551(95.3)$ & \\
\hline Educational level & & & & $<0.0001$ \\
\hline Elementary school or less & $43,401(69.1)$ & $3,582(8.3)$ & $39,819(91.8)$ & \\
\hline Middle school & $7,994(12.7)$ & $519(6.5)$ & $7,475(93.5)$ & \\
\hline High school & $7,980(12.7)$ & $478(6.0)$ & $7,502(94.0)$ & \\
\hline College or over & $3,470(5.5)$ & $150(4.3)$ & $3,320(95.7)$ & \\
\hline Labor status & & & & $<0.0001$ \\
\hline Active & $24,638(39.2)$ & $1,213(4.9)$ & $23,425(95.1)$ & \\
\hline Non-active & $38,207(60.8)$ & $3,516(9.2)$ & $34,691(90.8)$ & \\
\hline Perceived health status & & & & $<0.0001$ \\
\hline Good & $11,948(19.0)$ & $362(3.0)$ & $11,586(97.0)$ & \\
\hline Normal & $21,647(34.5)$ & $1,026(4.7)$ & $20,621(95.3)$ & \\
\hline $\mathrm{Bad}$ & $29,250(46.5)$ & $3,341(11.4)$ & $25,909(88.6)$ & \\
\hline Physical activity & & & & $<0.0001$ \\
\hline Insufficient & $51,345(81.7)$ & $4,018(7.8)$ & $47,327(92.2)$ & \\
\hline Sufficient & $11,500(18.3)$ & $711(6.2)$ & $10,789(93.8)$ & \\
\hline Perceived stress status & & & & $<0.0001$ \\
\hline Much & $12,703(20.2)$ & $4,018(7.8)$ & $47,327(92.2)$ & \\
\hline Little & $50,142(79.8)$ & $711(6.2)$ & $10,789(93.8)$ & \\
\hline
\end{tabular}


Table 1. General characteristics of the study population (continued)

\begin{tabular}{|c|c|c|c|c|}
\hline \multirow{2}{*}{ Variables } & \multirow{2}{*}{$\begin{array}{c}\text { Total }(\mathrm{N}=62,845) \\
\mathrm{N}(\%)\end{array}$} & \multicolumn{2}{|c|}{ Depressive symptoms } & \multirow{2}{*}{$\mathrm{p}$-value } \\
\hline & & Yes, N (\%) & No, N (\%) & \\
\hline Current drinker & & & & $<0.0001$ \\
\hline Yes & $27,124(43.2)$ & $1,673(6.2)$ & $25,451(93.8)$ & \\
\hline No & $35,721(56.8)$ & $3,056(8.6)$ & $32,665(91.4)$ & \\
\hline Current smoker & & & & 0.9548 \\
\hline Yes & $5,793(9.2)$ & $437(7.5)$ & $5,356(92.5)$ & \\
\hline No & $57,052(90.8)$ & $4,292(7.5)$ & $52,760(92.5)$ & \\
\hline Chronic diseases & & & & $<0.0001$ \\
\hline No & $18,296(24.6)$ & $1,016(5.2)$ & $17,280(94.8)$ & \\
\hline Yes & $44,549(33.6)$ & $3,713(6.7)$ & $40,836(93.3)$ & \\
\hline Total & $62,845(100.0)$ & $4,729(7.5)$ & $58,116(92.5)$ & \\
\hline
\end{tabular}

symptoms (OR: 1.12, 95\% CI: 1.02-1.23) compared to those who had contact more than once a week. Individuals who had contact with neighbors less than once a week were also significantly more likely to experience depressive symptoms (OR: 1.22 , 95\% CI: 1.10-1.35) compared to those who had contact more than once a week. The frequency of contact with friends did not show a significant association with depressive symptoms. Individuals with a spouse were significantly less likely to experience depressive symptoms (OR: 0.61, 95\% CI: 0.55$0.68)$ compared to individuals without a spouse, which included those who were divorced, widowed, separated, and who had never married. Individuals in the lowest income group showed significantly higher risk (OR: 2.00, 95\% CI: 1.58-2.53) than those in the highest income group. Individuals who were currently employed were significantly less likely to experience depressive symptoms (OR: 0.66, 95\% CI: 0.59-0.74).

Table 3 shows the results of subgroup analyses stratified by age group, having a spouse, income level, and employment status. Among participants aged 80 years or older, those who had contact with neighbors less than once a week were significantly more likely to experience depressive symptoms (OR: 1.55, 95\% CI: 1.28-1.87) compared to those who had contact more than once a week. In the oldest group, the frequency of contact with relatives and friends was not significantly associated with depressive symptoms. Among participants without a spouse, those who had contact with neighbors less than once a week were significantly more likely to experience depressive symptoms (OR: 1.33, 95\% CI: 1.17-1.52) compared to those who more often had contact with neighbors. Among participants with a spouse, those who had contact with friends less than once a week were significantly more likely to experience depressive symptoms (OR: 1.19, 95\% CI: 1.05-1.36) compared to those who had frequent contact. In the lowest income group, individuals who had contact with relatives (OR: 1.28, 95\% CI: 1.15-1.43) and neighbors (OR: 1.26, 95\% CI:
1.12-1.43) less than once a week were more likely to have depressive symptoms. Among currently employed participants, individuals who had contact with relatives less than once a week were more likely to experience depressive symptoms (OR: 1.31, 95\% CI: 1.11-1.56). Among non-working participants, those who had contact with neighbors less than once a week were more likely to experience depressive symptoms (OR: 1.24, 95\% CI: 1.11-1.39).

Figure 1 shows the association between frequent social contact and depressive symptoms. Individuals who frequently had contact with both neighbors and friends were significantly less likely to experience depressive symptoms (OR: 0.80, 95\% CI: 0.67-0.94). Those who had frequent contact with both neighbors and relatives were significantly less likely to experience depressive symptoms (OR: 0.73, 95\% CI: $0.63-$ 0.86). Lastly, individuals who had frequent contact with neighbors, relatives, and friends were significantly less likely to experience depressive symptoms (OR: $0.68,95 \%$ CI: 0.58-0.80).

\section{DISCUSSION}

The results of the present study revealed that depressive symptoms were significantly associated with the frequency of certain social contacts among elderly Koreans. Individuals who rarely had contact with relatives or neighbors were significantly more likely to experience depressive symptoms than those who had frequent contact with relatives or neighbors, although no significant results were shown for the frequency of contact with friends. Furthermore, individuals who rarely had contact with neighbors had a significantly higher risk of experiencing depressive symptoms compared to that in the reference group. In addition, having a spouse, income level, and working status were significantly associated with depressive symptoms in older adults. The associations between higher risk of depressive symptoms and less contact with relatives, ${ }^{13}$ 
Table 2. Factors associated with depressive symptoms

\begin{tabular}{|c|c|c|}
\hline \multirow{2}{*}{ Variables } & \multicolumn{2}{|c|}{ Depressive symptoms } \\
\hline & Adj. OR & $95 \% \mathrm{CI}$ \\
\hline \multicolumn{3}{|l|}{ Contact with relatives } \\
\hline$<$ Once a week & 1.12 & $1.02-1.23$ \\
\hline$\geq$ Once a week & 1.00 & \\
\hline \multicolumn{3}{|l|}{ Contact with neighbors } \\
\hline$<$ Once a week & 1.22 & $1.10-1.35$ \\
\hline$\geq$ Once a week & 1.00 & \\
\hline \multicolumn{3}{|l|}{ Contact with friends } \\
\hline$<$ Once a week & 1.07 & $0.97-1.17$ \\
\hline$\geq$ Once a week & 1.00 & \\
\hline \multicolumn{3}{|l|}{ Age (years) } \\
\hline $65-69$ & 1.31 & $1.13-1.52$ \\
\hline $70-74$ & 1.16 & $1.01-1.33$ \\
\hline $75-79$ & 1.05 & $0.91-1.21$ \\
\hline$\geq 80$ & 1.00 & \\
\hline \multicolumn{3}{|l|}{ Sex } \\
\hline Men & 0.84 & $0.74-0.95$ \\
\hline Women & 1.00 & \\
\hline \multicolumn{3}{|l|}{ Existence of spouse } \\
\hline Yes & 0.61 & $0.55-0.68$ \\
\hline No & 1.00 & \\
\hline \multicolumn{3}{|l|}{ Monthly income } \\
\hline Low & 2.00 & $1.58-2.53$ \\
\hline Lower-middle & 1.50 & $1.17-1.91$ \\
\hline Upper-middle & 1.17 & $0.88-1.57$ \\
\hline High & 1.00 & \\
\hline \multicolumn{3}{|l|}{ Educational level } \\
\hline Elementary school or less & 1.00 & $0.80-1.26$ \\
\hline Middle school & 1.16 & $0.90-1.49$ \\
\hline High school & 1.19 & $0.93-1.53$ \\
\hline College or over & 1.00 & \\
\hline \multicolumn{3}{|l|}{ Labor status } \\
\hline Active & 0.66 & $0.59-0.74$ \\
\hline Non-active & 1.00 & \\
\hline \multicolumn{3}{|l|}{ Perceived health status } \\
\hline Good & 0.46 & $0.39-0.54$ \\
\hline Normal & 0.64 & $0.57-0.72$ \\
\hline $\mathrm{Bad}$ & 1.00 & \\
\hline \multicolumn{3}{|l|}{ Physical activity } \\
\hline Insufficient & 1.02 & $0.89-1.17$ \\
\hline Sufficient & 1.00 & \\
\hline \multicolumn{3}{|l|}{ Perceived stress status } \\
\hline Much & 6.23 & $5.67-6.84$ \\
\hline Little & 1.00 & \\
\hline
\end{tabular}

Table 2. Factors associated with depressive symptoms (continued)

\begin{tabular}{lcc}
\hline \multirow{2}{*}{ Variables } & \multicolumn{2}{c}{ Depressive symptoms } \\
\cline { 2 - 3 } & Adj. OR & $95 \%$ CI \\
\hline Current drinker & & \\
$\quad$ Yes & 0.96 & $0.87-1.06$ \\
No & 1.00 & \\
Current smoker & & \\
$\quad$ Yes & 1.09 & $0.93-1.28$ \\
$\quad$ No & 1.00 & \\
Chronic diseases & & \\
No & 1.00 & \\
Yes & 1.10 & $0.98-1.23$ \\
\hline
\end{tabular}

OR: odds ratio, CI: confidence interval

less contact with neighbors, ${ }^{14}$ not having a spouse, ${ }^{15}$ lower income level ${ }^{16}$ and active employment ${ }^{17}$ show similar tendencies to those of previous studies on associations with depression in older adults.

The results of subgroup analyses revealed that many demographic and socioeconomic factors were associated with contact with neighbors and depressive symptoms in older adults. The subgroup analyses of the frequency of contact with neighbors revealed that age, having a spouse, income level, and employment status were significantly associated with depressive symptoms. Age, specifically the 65-69 years, $75-79$ years, and 80 years or older groups that rarely had contact with neighbors, was significantly associated with depressive symptoms compared to individuals who often had contact with neighbors. The analyses according to age groups revealed that the eldest group ( $\geq 80$ years) required increased contact with neighbor compared to the other age groups. As people age, health conditions deteriorate, and physical illness is correlated with depressive symptoms. ${ }^{18}$ Korean older adults tend to consider their neighbors closer than their relatives, and one of the reasons is that everybody in a town helped each other in the days of agriculture, ${ }^{19}$ and this tradition still affects older adults' social networking. In addition, the prevalence of the Korean traditional extended family that includes three generations or more is decreasing, ${ }^{20}$ and adult children often live in different places and rarely contact each other because of their hectic lives. In this context, the Korean elderly tend to rely more on neighbors than on relatives. Moreover, the cases of lonely death in older adults are increasing nationwide ${ }^{21}$ making the role of neighbors more important than ever. Neighbors could informally monitor and help each other. ${ }^{22}$ Therefore, contact with nearby neighbors is necessary in order to reduce loneliness and depressive symptoms in the Korean elderly, especially those aged 80 years or older. Individuals without a spouse, unemployed individuals, and individuals with low income 
were also significantly associated with experiencing depressive symptoms if they seldom had contact with neighbors. A spouse plays a crucial role as a lifetime companion for older adults. ${ }^{23}$ Thus, if individuals experience major life events such as the loss of a spouse to rely on or retirement from jobs, they may feel isolated in their later $\operatorname{life}^{24}$ and may find someone

Table 3. Subgroup analysis of the association between social contacts and depressive symptoms stratified by age, having a spouse, income, and labor status

\begin{tabular}{|c|c|c|c|c|c|c|c|c|c|}
\hline \multirow{4}{*}{ Variables } & \multicolumn{9}{|c|}{ Depressive symptoms } \\
\hline & \multicolumn{3}{|c|}{ Contact with relatives } & \multicolumn{3}{|c|}{ Contact with neighbors } & \multicolumn{3}{|c|}{ Contact with friends } \\
\hline & \multicolumn{2}{|c|}{$<$ Once a week } & \multirow{2}{*}{$\frac{\geq \text { Once a week }}{\text { Adj. OR }}$} & \multicolumn{2}{|c|}{$<$ Once a week } & \multirow{2}{*}{$\frac{\geq \text { Once a week }}{\text { Adj. OR }}$} & \multicolumn{2}{|c|}{$<$ Once a week } & \multirow{2}{*}{$\frac{\geq \text { Once a week }}{\text { Adj. OR }}$} \\
\hline & Adj. OR & $95 \% \mathrm{CI}$ & & Adj. OR & $95 \% \mathrm{CI}$ & & Adj. OR & $95 \% \mathrm{CI}$ & \\
\hline \multicolumn{10}{|l|}{ Age (years) } \\
\hline $65-69$ & 1.13 & $0.96-1.33$ & 1.00 & 1.20 & $1.01-1.43$ & 1.00 & 1.19 & $1.00-1.40$ & 1.00 \\
\hline $70-74$ & 1.11 & $0.96-1.29$ & 1.00 & 1.10 & $0.94-1.30$ & 1.00 & 1.01 & $0.87-1.17$ & 1.00 \\
\hline $75-79$ & 1.15 & $0.98-1.35$ & 1.00 & 1.22 & $1.01-1.49$ & 1.00 & 1.04 & $0.88-1.24$ & 1.00 \\
\hline$\geq 80$ & 1.14 & $0.96-1.36$ & 1.00 & 1.55 & $1.28-1.87$ & 1.00 & 0.98 & $0.81-1.18$ & 1.00 \\
\hline \multicolumn{10}{|c|}{ Existence of spouse } \\
\hline Yes & 1.13 & $0.99-1.28$ & 1.00 & 1.13 & $0.98-1.30$ & 1.00 & 1.19 & $1.05-1.36$ & 1.00 \\
\hline No & 1.12 & $0.99-1.27$ & 1.00 & 1.33 & $1.17-1.52$ & 1.00 & 0.94 & $0.83-1.07$ & 1.00 \\
\hline \multicolumn{10}{|l|}{ Monthly income } \\
\hline Low & 1.28 & $1.15-1.43$ & 1.00 & 1.26 & $1.12-1.43$ & 1.00 & 1.06 & $0.94-1.19$ & 1.00 \\
\hline Lower-middle & 0.95 & $0.80-1.12$ & 1.00 & 1.26 & $1.06-1.51$ & 1.00 & 1.03 & $0.87-1.22$ & 1.00 \\
\hline Upper-middle & 0.93 & $0.68-1.27$ & 1.00 & 0.97 & $0.69-1.37$ & 1.00 & 1.20 & $0.87-1.66$ & 1.00 \\
\hline High & 1.12 & $0.75-1.67$ & 1.00 & 1.06 & $0.72-1.55$ & 1.00 & 1.18 & $0.77-1.79$ & 1.00 \\
\hline \multicolumn{10}{|l|}{ Labor status } \\
\hline Active & 1.31 & $1.11-1.56$ & 1.00 & 1.11 & $0.89-1.38$ & 1.00 & 0.95 & $0.81-1.12$ & 1.00 \\
\hline Non-active & 1.08 & $0.98-1.20$ & 1.00 & 1.24 & $1.11-1.39$ & 1.00 & 1.10 & $0.98-1.22$ & 1.00 \\
\hline
\end{tabular}

OR: odds ratio, CI: confidence interval

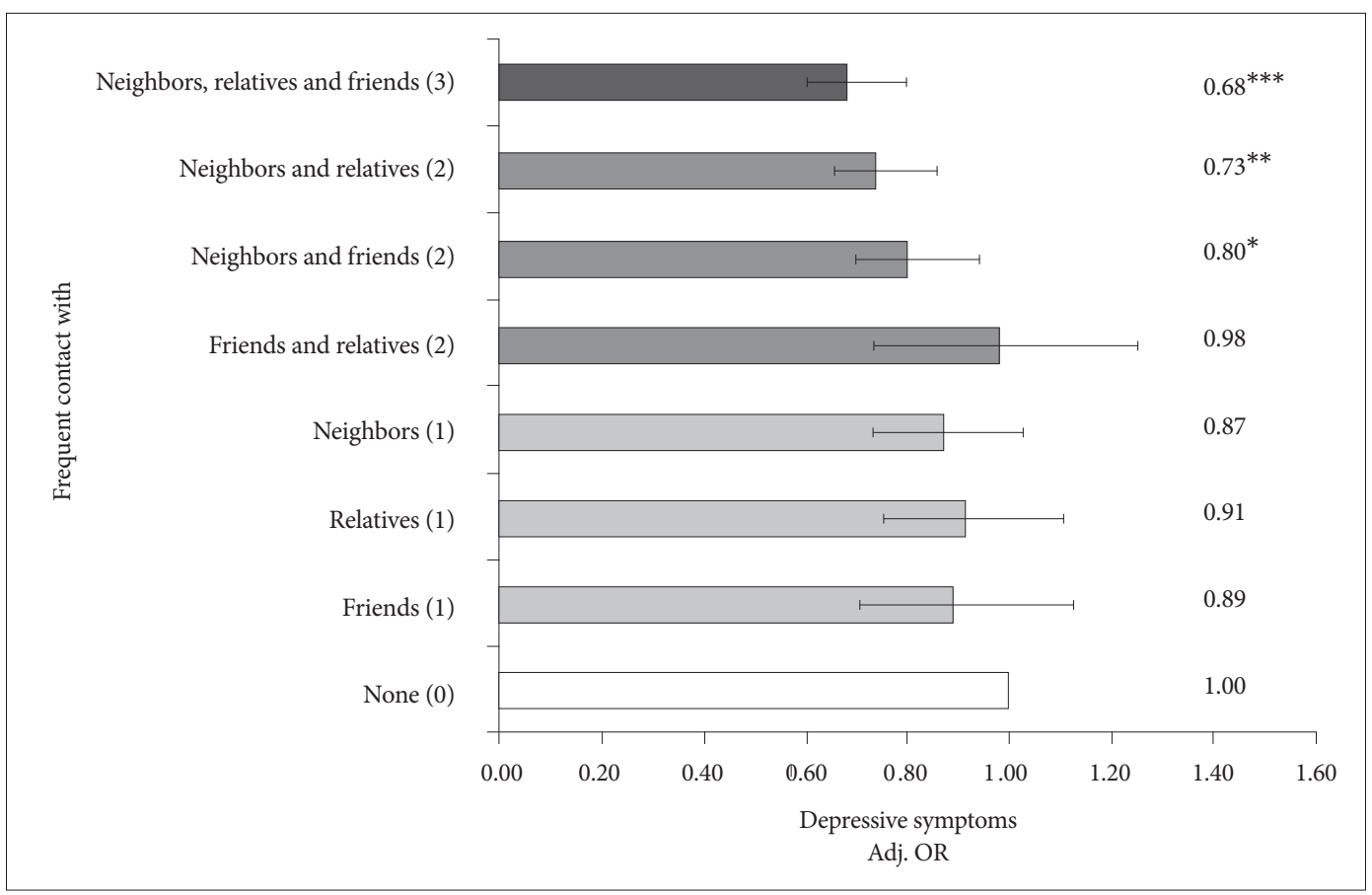

Figure 1. Depressive symptoms by the combination of frequent social contact groups. Figure 1 shows the association between frequent social contact ( $\geq$ once a week) and depressive symptoms. All other variables are adjusted. ${ }^{*} p<0.05,{ }^{* *} p<0.01,{ }^{* * *} p<0.001$. OR: odds ratio. 
with whom they can easily interact. Neighbors exist within a limited space, facilitating face-to-face contact. ${ }^{25}$ Thus, neighbors play important roles as later-life friends ${ }^{26}$ and contact with neighbors can improve depressive symptoms in individuals without a spouse, unemployed individuals, and low-income individuals.

Subgroup analyses on the frequency of contact with relatives revealed that income level and employment status were significantly associated with depressive symptoms. Individuals who were in the lowest income group were significantly associated with experiencing depressive symptoms if they rarely had contact with relatives. The economic status of older adults plays an important role in determining the level of depression in South Korea. ${ }^{27}$ Thus, it is important for low-income elderly to reduce the risk of depressive symptoms. Interacting with both relatives and neighbors might be one way to decrease depressive symptoms, as we have already shown in the results of the subgroup analyses on the frequency of contact with neighbors. Regarding employment status, individuals who were economically active were also significantly associated with experiencing depressive symptoms if they rarely had contact with relatives. Employed individuals spend much time in the workplace and can communicate with colleagues while working. Thus, contact with neighbors or friends might not have a great effect on their depressive moods.

Interestingly, the subgroup analyses on the frequency of contact with friends revealed that only having a spouse was significantly associated with depressive symptoms. Individuals with a spouse were significantly associated with experiencing depressive symptoms if they rarely contacted with friends. Married individuals might rely on a spouse for suppor $\mathrm{t}^{28}$ and can communicate with a spouse whenever they want. Therefore, they might not have strong needs for contact with someone else living nearby.

Finally, individuals who had frequent contact with both neighbors and friends, both neighbors and relatives, or all three groups showed a significant association with depressive symptoms, while other combinations of social contacts did not show the significant results. The results of our study indicate that, among social relationships, contact with neighbors is the most powerful factor associated with depressive symptoms in Korean older adults.

The present study has several strengths. First, we used CHS data performed by a national institution; these data are statistically reliable and representative compared to those produced by surveys performed by private institutions. In addition, although previous studies have assessed the associations between social support and depression among older adults, our study mainly focused on associations between different types of social contacts and depressive symptoms among old- er adults, stratified by demographic and socioeconomic factors. The present study also has several limitations. First, a causal relationship could not be established between the frequency of social contacts and depressive symptoms since the CHS was a cross-sectional survey. Second, we used self-reported questionnaire to identify the existence of depressive symptoms. Third, we did not exclude participants who were diagnosed with clinical depression. Fourth, the CHS data do not provide additional information on social contacts such as the size of and individual satisfaction with the social networks. The addition of these data might improve our findings on the relationships between social contacts and depressive symptoms among elderly Koreans.

Our study found that the frequency of social contact was significantly associated with depressive symptoms in older adults. In particular, many factors were associated with less contact with neighbors and the incidence of depressive symptoms. Moreover, analysis of association between frequent social contact groups and depressive symptoms revealed that, among other social relationships, frequent contact with neighbors was the most important protect factor associated with older adults' depressive symptoms. There are various types of community institutions for older adults in South Korea, including so-called 'senior welfare centers'. There are approximately 460 enrolled senior welfare centers nationwide in 2017. ${ }^{29}$ They provide programs to older adults in the local community, such as exercise, singing, foreign language conversation, and volunteering ${ }^{30}$ and also provide older adults with more opportunities to have close neighbors and to interact with them while learning and talking with each other. The establishment of additional community centers and more free classes might reduce the loneliness experienced by older adults and their risks of experiencing depressive symptoms.

\section{REFERENCES}

1. Statistics Korea. Population and Housing Census. Daejeon: Statistics Korea; 2016.

2. Park JI, Park TW, Yang JC, Chung SK. Factors associated with depression among elderly Koreans: the role of chronic illness, subjective health status, and cognitive impariment. Psychogeriatrics 2016;6:62-69.

3. Solhaug HI, Romuld EB, Romild U, Stordal E. Increased prevalence of depression in cohorts of the elderly: an 11-year follow-up in the general population-the HUNT study. Int Psychogeriatr 2012;24:151-158.

4. Organization for Economic Cooperation and Development. Health at a Glance: OECD Indicators. Paris: OECD Publishing; 2016.

5. Park JY, Han JW, Jeong H, Jeong HG, Kim TH, Yoon IY, et al. Suicidal behaviors in elderly Koreans: one-month-point prevalence and factors related to suicidality. J Affect Disord 2013;150:77-83.

6. Conwell Y, Duberstein PR, Cox C, Herrmann J, Forbes N, Caine ED. Age differences in behaviors leading to completed suicide. Am J Geriatr Psychiatry 1998;6:122-126.

7. Statistics Korea. Future Household Estimation. Daejeon: Statistics Korea; 2017.

8. Birren JE, Schaie KW. Handbook of the Psychology of Aging (5th Ed). 
In: Antonucci TC, Editor. Social Relations an Examination of Social Networks, Social Support. London: Elsevier, 2001, p.427-453.

9. Kahn RL, Antonucci TC. Convoys over the life course: attachment, roles, and social support. Life Span Dev Behav 1980;3:253-286.

10. Fiori KL, Smith J, Antonucci TC. Social network types among older adults: a multidimensional approach. J Gerontol B Psychol Sci Soc Sci 2007;62:322-330.

11. Aneshensel CS, Stone JD. Stress and depression: a test of the buffering model of social support. Arch Gen Psychiatry 1982;39:1392-1396.

12. Chen R, Wei L, Hu Z, Qin X, Copeland JM, Hemingway H. Depression in older people in rural China. Arch Intern Med 2005;165:20192025.

13. Rho B, Mo SH. The effect of levels and dimensions of social support on geriatric depression. J Kor Gerontol Soc 2007;27:53-69.

14. Adams KB, Sanders S, Auth E. Loneliness and depression in independent living retirement communities: risk and resilience factors. Aging Ment Health 2004;8:475-485.

15. Hybels CF, Blazer DG, Pieper CF. Toward a threshold for subthreshold depression: an analysis of correlates of depression by severity of symptoms using data from an elderly community sample. Gerontologist 2001; 41:357-365

16. Leaf PJ, Berkman CS, Weissman MM, Holzer III CE, Tischler GL, Myers J. The Epidemiology of Late-life Depression. Epidemiology and Aging: an International Perspective. New York: Springer Publishing Company; 1988.

17. Lee S, Lee G. A study on the major factors influencing the depression among the elderly in rural area. J Korea Gerontol Soc 2002;22:209-226.

18. Williamson GM, Schulz R. Pain, activity restriction, and symptoms of depression among community-residing elderly adults. J Gerontol 1992; 47:367-372.

19. Oh K, Lee SO, Kim JA, Jeong CJ, Oh KO, Kim HS. Search for the mean- ing of social support in Korean society. J Nurs Acad Soc 1994;24:264277.

20. Oh DH, Park JH, Lee HY, Kim SA, Choi BY, Nam JH. Association between living arrangements and depressive symptoms among older women and men in South Korea. Soc Psychiatry Psychiatr Epidemiol 2015;50:133-141.

21. Lee SH, Lee HS. A study on the smart services for managing solitary death of the elderly who live alone. J Kor Hous Assoc 2013;85-89.

22. Wenger GC. The special role of friends and neighbors. J Aging Stud 1990;4:149-169.

23. Kwon OG, Hur JS. Determinants of marital satisfaction among the elderly couple. J Welfare Aged Institute 2010;47:7-29.

24. Hawkley LC, Cacioppo JT. Loneliness matters: a theoretical and empirical review of consequences and mechanisms. Ann Behav Med 2010;40:218-227.

25. Bulmer M. Neighbours: the Work of Philip Abrams. New York: Cambridge University Press; 1986.

26. Arling G. The elderly widow and her family, neighbors and friends. J Marriage Fam 1976;38:757-768.

27. Ko HN, Lee SS, Han HJ. The prevalence of depression and its related factors of the elderly in rural area. J Korean Acad Psychiatr Ment Health Nurs 2001;10:645-655.

28. Wu Z, Pollard MS. Social support among unmarried childless elderly persons. J Gerontol Series B 1998;53B:S324-S335.

29. Association of Social Welfare Center. Nationwide Social Welfare Center Total Number. Available at: http://kaswc.or.kr/centerlist. Accessed August 29, 2017.

30. Cho H, Seo H. Needs and satisfaction of the senior citizens who join in the programs administered by the senior welfare center. Korean J Res Gerontol 2004;13:113-130. 